\title{
Polarimetric radar and in situ observations of riming and snowfall microphysics during CLACE 2014
}

\author{
J. Grazioli ${ }^{1}$, G. Lloyd ${ }^{2}$, L. Panziera ${ }^{1}$, C. R. Hoyle ${ }^{3,4}$, P. J. Connolly ${ }^{2}$, J. Henneberger ${ }^{5}$, and A. Berne ${ }^{1}$ \\ ${ }^{1}$ Environmental Remote Sensing Laboratory (LTE), École Polytechnique Fédérale de Lausanne (EPFL), \\ Lausanne, Switzerland \\ ${ }^{2}$ Centre for Atmospheric Science, University of Manchester, Manchester, UK \\ ${ }^{3}$ Laboratory of Atmospheric Chemistry, Paul Scherrer Institute (PSI), Villigen, Switzerland \\ ${ }^{4}$ WSL Institute for Snow and Avalanche Research SLF, Davos, Switzerland \\ ${ }^{5}$ Institute for Atmospheric and Climate Science, ETH, Zurich, Switzerland \\ Correspondence to: A. Berne (alexis.berne@epfl.ch)
}

Received: 5 June 2015 - Published in Atmos. Chem. Phys. Discuss.: 2 July 2015

Revised: 16 October 2015 - Accepted: 10 November 2015 - Published: 15 December 2015

\begin{abstract}
This study investigates the microphysics of winter alpine snowfall occurring in mixed-phase clouds in an inner-Alpine valley during January and February 2014. The available observations include high-resolution polarimetric radar and in situ measurements of the ice-phase and liquidphase components of clouds and precipitation. Radar-based hydrometeor classification suggests that riming is an important factor to favor an efficient growth of the precipitating mass and correlates with snow accumulation rates at ground level. The time steps during which rimed precipitation is dominant are analyzed in terms of temporal evolution and vertical structure. Snowfall identified as rimed often appears after a short time period during which the atmospheric conditions favor wind gusts and updrafts and supercooled liquid water (SLW) is available. When a turbulent atmospheric layer persists for several hours and ensures continuous SLW generation, riming can be sustained longer and large accumulations of snow at ground level can be generated. The microphysical interpretation and the meteorological situation associated with one such event are detailed in the paper. The vertical structure of polarimetric radar observations during intense snowfall classified as rimed shows a peculiar maximum of specific differential phase shift $K_{\mathrm{dp}}$, associated with large number concentrations and riming of anisotropic crystals. Below this $K_{\text {dp }}$ peak there is usually an enhancement in radar reflectivity $Z_{\mathrm{H}}$, proportional to the $K_{\mathrm{dp}}$ enhancement and interpreted as aggregation of ice crystals. These signatures seem to be recurring during intense snowfall.
\end{abstract}

\section{Introduction}

Precipitation of ice-phase hydrometeors is the result of the interactions between cloud ice crystals, supercooled liquid water (SLW) droplets and water vapor. After nucleation, the processes of vapor deposition, aggregation, and riming all contribute to the growth of the crystals up to the point where they begin to fall and further interact with the lower layers of the atmosphere (e.g., Pruppacher and Klett, 1997; Cantrell and Heymsfield, 2005; Straka and Mansell, 2005). The characteristics of the ice-phase hydrometeors at ground level depend on the full falling history and on all the microphysical interactions occurring between nucleation and the time the hydrometeor reaches the ground.

The shape, density, and growth rate of individual crystals are mostly a function of temperature and relative humidity of the environment in which they form (Magono and Lee, 1966; Chen and Lamb, 1994; Fukuta and Takahashi, 1999; Bailey and Hallett, 2009; Takahashi, 2014). Individual crystals can clump together (aggregation) and/or collect supercooled liquid water droplets that freeze upon impact on the surface of the crystals (riming). Riming leads to a net increase in the mass of precipitating snowflakes (ice phase) at the expense of the liquid phase. Aggregation contributes indirectly to this mass transfer by generating larger and faster targets for riming (Houze and Medina, 2005, hereafter HM2005).

Riming is more efficient on large crystals (Ono, 1969), even though it was recently shown that the process can also 
occur on very small crystals, with characteristic dimensions as small as $60 \mu \mathrm{m}$ (Avila et al., 2009). Turbulence and vertical air motion (updraft) contribute significantly to riming. Turbulence, or motion variability, influences the trajectories of ice crystals, leading to larger droplet collection volumes and therefore large collection efficiencies (Pinsky and Khain, 1998). Updraft, in turn, is necessary to sustain the production of SLW (Rauber and Tokay, 1991).

The impact of riming on the bulk properties of snowfall is critical. Measurements of freshly fallen snow, both in the Sierra Nevada (USA) and in the proximity of Sapporo (Japan), showed that 30 to $60 \%$ of the total mass of snowfall is constituted by frozen SLW droplets on the snowflakes, also called rimed accretion (Harimaya and Sato, 1989; Mitchell et al., 1990). Additionally, the accumulation of heavily rimed snowflakes (graupel) on the ground is more prone to generate instabilities and to initiate avalanches (Abe, 2004). One last aspect to consider is that during precipitation riming can be associated with ice splintering and thus (secondary) ice generation. The most known example of secondary ice production is the Hallett-Mossop ice multiplication mechanism (Hallett and Mossop, 1974) occurring at temperatures higher than $-8^{\circ} \mathrm{C}$ on heavily rimed hydrometeors. However, other mechanisms exist to explain secondary ice generation at colder temperatures. One example is constituted by iceice and ice-water collisional mechanisms (Vardiman, 1978; Yano and Phillips, 2011), that are in any case favored by the degree of riming of the colliding crystals. Non-collisional mechanisms have been hypothesized as well. For instance, Rangno (2008) described the process of fragmentation of freezing supercooled droplets in mixed-phase clouds, and recently Lloyd et al. (2015) hypothesized that the lifting and transport of hoarfrost crystals from the ground to the clouds could explain the very high concentration of small crystals frequently observed in low level winter clouds.

Dual-polarization Doppler (polarimetric) weather radars operating at microwave frequencies are becoming state-ofthe-art instruments to document the microphysics of icephase precipitation. These systems are able to provide indirect information about size, intensity, geometry, density, velocity and turbulence of falling hydrometeors (e.g., Bringi and Chandrasekar, 2001; Doviak and Zrnić, 2006). Polarimetric data have been used to identify areas of intense growth of dendritic and planar crystals (Kennedy and Rutledge, 2011; Bechini et al., 2013; Schrom et al., 2015) and to formulate hypotheses on the dominant microphysical processes occurring at various altitude levels during snowfall (Schneebeli et al., 2013; Andric et al., 2013; Kumjian et al., 2014). The combination of numerical modeling, radar observations and in situ data led to the development of classification methods aiming to estimate the dominant type of hydrometeors that populate the radar resolution volumes (e.g., Straka et al., 2000; Dolan and Rutledge, 2009; Bechini and Chandrasekar, 2015; Grazioli et al., 2015). However, the complex microphysics of ice-phase precipitation cannot be fully captured by polarimetric radars alone, nor simply described by a single hydrometeor type. Combinations of remote sensing with in situ instruments have shown to be useful and often necessary to better characterize precipitation, clouds, and environmental conditions (Hogan et al., 2002, 2003; Bechini et al., 2013, hereafter BBC2013). Despite several years of research and technological development, many microphysical processes of winter precipitation in complex terrains remain poorly understood.

This paper presents results of an investigation into the relation between snowfall microphysics and intensity, the temporal evolution and the vertical structure of intense winter precipitation events originating in mixed-phase clouds based on polarimetric radar and in situ observations collected during winter alpine snowfall. The paper is structured as follows: Sect. 2 provides information about the main instrumental setup. Section 3 presents the analyses that relate rimed precipitation with snow accumulation as well as a microphysical description of the vertical structure of precipitation. Section 4 is devoted to the detailed description of a particularly intense snowfall event characterized by a long-lasting turbulent layer in the atmosphere. Finally, Sect. 5 summarizes the main results and provides conclusions and perspectives.

\section{Measurement campaign and instruments}

The measurements shown in this paper were collected during the Cloud and Aerosol Characterization Experiment (CLACE), occurring in January and February 2014. The CLACE campaigns have been conducted almost every year since 2000. They are based at the high-alpine research station on the Jungfraujoch, in the Swiss Alps at an altitude of $3580 \mathrm{~m}$ (e.g., Zieger et al., 2012).

\subsection{Instruments}

Figure 1 shows the location of the three main measurement sites considered in the present work: Kleine Scheidegg (KS, $2061 \mathrm{~m}$ ), Männlichen (MAE, $2230 \mathrm{~m}$ ), and Jungfraujoch (JFJ, $3580 \mathrm{~m})$. The topography of the measurement area is very complex, with mountain peaks above $4000 \mathrm{~m}$ and steep elevation gradients.

\subsubsection{Kleine Scheidegg (KS)}

A polarimetric Doppler weather radar was deployed at the KS location. The system, named MXPol, is an X-band $(3.2 \mathrm{~cm}$ wavelength) radar with angular resolution of about $1.5^{\circ}$ and range resolution of $75 \mathrm{~m}$ (complete specifications are given in Schneebeli et al., 2013; Scipion et al., 2013). MXPol provides as main products the reflectivity factor at horizontal polarization $Z_{\mathrm{H}}(\mathrm{dBZ})$, differential reflectivity $Z_{\mathrm{DR}}(\mathrm{dB})$, copolar cross-correlation coefficient $\rho_{\mathrm{hv}}$, specific differential phase shift upon propagation $K_{\mathrm{dp}}\left({ }^{\circ} \mathrm{km}^{-1}\right)$, mean Doppler velocity $v\left(\mathrm{~m} \mathrm{~s}^{-1}\right)$ and Doppler spectrum width 


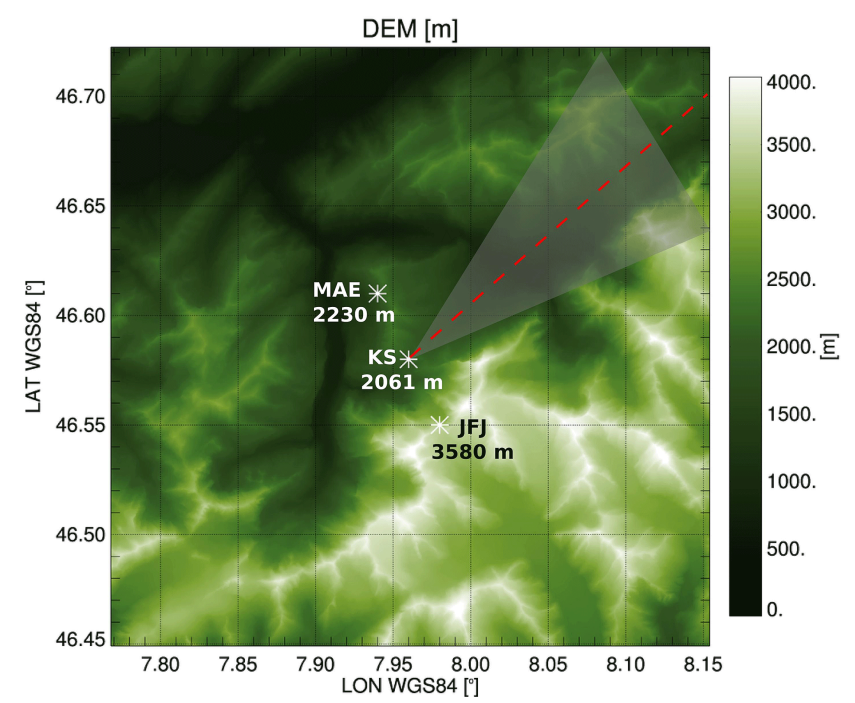

Figure 1. Location of the main measurement sites of CLACE 2014 that are considered here. The locations are highlighted on a digital elevation model of the area. The gray shading highlights the area of the domain covered by radar PPIs, while the red line indicates the direction of the RHI employed in the analysis of the paper. The coordinates shown on the map are expressed in the World Geodesic System 1984 (WGS84) reference.

$\sigma_{v}$ (Doviak and Zrnić, 2006). A hydrometeor classification method (Grazioli et al., 2015, hereafter GTB2015) was developed based on clustering techniques and applied to the polarimetric data. GTB2015 classifies dry snowfall into three broad categories: aggregates (AG), individual crystals (CR), rimed ice particles (RI).

During CLACE 2014, MXPol was operating with a scanning sequence of about $4.5 \mathrm{~min}$, repeated indefinitely. In this paper we will employ plan position indicator (PPI) scan data collected at an elevation of $10^{\circ}$ over the Grindelwald Valley $\left(\approx 45^{\circ}\right.$ northeast of KS in Fig. 1), range height indicator (RHI) scans collected over the Grindelwald Valley and vertical profiles ( $25 \mathrm{~s}$ duration) collected three times during each sequence. The maximum range distance sampled by MXPol during CLACE was about $20 \mathrm{~km}$. During vertical profiling, full Doppler power spectra were collected, providing the Doppler velocity and Doppler spectral width as moments of the Doppler spectrum (e.g., Doviak and Zrnić, 2006)

\subsubsection{Männlichen (MAE)}

At the MAE site, snow height on the ground was measured by an automatic station whose data are made available by MeteoSwiss. Time series of snow height measurements in time are used to quantify snow accumulations and accumulation rates of the precipitation events. Among other gauging stations in this area, MAE is chosen as a reference because (i) it provides relatively high temporal resolution data (30 min), (ii) it is among the closest to KS and (iii) it is lo- cated approximately at the altitude of the first radar resolution volume not affected by ground clutter and radar blind range, and because (iv) the accumulation trends measured at the other stations in this area and during the study period are very similar (thus the wind and post-depositional processes were influencing the stations in a similar way).

\subsubsection{Jungfraujoch (JFJ)}

The JFJ observatory is a well-known site for atmospheric studies of aerosols and clouds (e.g., Baltensperger et al., 1997), and during CLACE 2014 it accommodated several sensors. The ones that are of direct interest for the present work are listed here. A weather station managed by MeteoSwiss provided general meteorological information and a sonic anemometer provided high-resolution wind information. A cloud droplet probe (CDP-100; Lance et al., 2010) yielded quantification of SLW content. The CDP measures the light scattered by droplets and determines the optical equivalent diameter over the size range 2 to $50 \mu \mathrm{m}$ at a $1 \mathrm{~Hz}$ acquisition frequency. A three-view cloud particle imager (3V-CPI) provided images and habits of liquid and ice-phase hydrometeors in the 10 to $1280 \mu \mathrm{m}$ size range. This instrument is the combination of a two-dimensional stereoscopic (2D-S; Lawson et al., 2006) laser shadow imaging probe and of a high-frame-rate cloud particle imager (CPI model 2) probe. The 2D-S component of the $3 \mathrm{~V}$-CPI instrument was used to analyze particle imagery in order to produce information on the concentration, size and phase of cloud particles.

The in situ sensor at the JFJ site and the polarimetric radar (KS site, Fig. 1), both continuously acquiring data, allow the contextualization of radar observations with respect to the cloud conditions over long time intervals. This is a definite added value of CLACE 2014. Similar comparisons between radars and cloud probes have in fact otherwise been performed only on limited time intervals, the cloud probes being usually aircraft-borne (e.g., Hogan et al., 2002, 2003; Houze and Medina, 2005).

\subsection{Precipitation events}

The months of January and February 2014 were relatively rich in terms of precipitation. By means of visual inspection of all the observations collected by MXPol, 13 precipitation events occurring in the measurement domain have been identified. These events have been summarized in Table 1. One event (event 9 in the table) is listed for the sake of completeness, but it will not be included in the following analysis. In this specific case, radar data were missing for technical reasons for more than $40 \%$ of the duration of the event.

\section{Analysis of rimed precipitation}

This section focuses on the relation between riming and snowfall accumulation as well as the vertical and temporal 
Table 1. List of the 13 precipitation events identified by means of radar data during CLACE 2014. The net duration of the events includes only time intervals during which precipitation was observed at the lowest available radar resolution volume, while the net snow accumulation is obtained from the MeteoSwiss MAE station (see Fig. 1). Bold is used to highlight one event during which the radar was significantly affected by technical issues.

\begin{tabular}{lrrrr}
\hline $\begin{array}{l}\text { Event } \\
\text { number }\end{array}$ & $\begin{array}{r}\text { Start (UTC) } \\
\text { MM-DD HH }\end{array}$ & $\begin{array}{r}\text { End (UTC) } \\
\text { MM-DD HH }\end{array}$ & $\begin{array}{r}\text { Duration } \\
(\mathrm{h})\end{array}$ & $\begin{array}{r}\text { Net snow } \\
\text { accumulation (cm) }\end{array}$ \\
\hline 1 & $01-3014$ & $01-3023$ & 10 & 1 \\
2 & $01-3104$ & $01-3117$ & 10 & 2 \\
3 & $02-0108$ & $02-0216$ & 28.5 & 29 \\
4 & $02-0316$ & $02-0412$ & 18 & 6 \\
5 & $02-0506$ & $02-0522$ & 8 & 6 \\
6 & $02-0707$ & $02-0719$ & 10 & 14 \\
7 & $02-0809$ & $02-0901$ & 8 & 5 \\
8 & $02-0922$ & $02-1004$ & 2 & 0 \\
$\mathbf{9}$ & $\mathbf{0 2 - 1 4 0 9}$ & $\mathbf{0 2}-14 \mathbf{1 9}$ & $\mathbf{3}$ & $\mathbf{0}$ \\
10 & $02-1522$ & $02-1705$ & 28 & 2 \\
11 & $02-1902$ & $02-1920$ & 13 & 14 \\
12 & $02-2021$ & $02-2121$ & 14 & 7 \\
13 & $02-2215$ & $02-2321$ & 8 & \\
\hline
\end{tabular}

evolution of precipitation cases showing the signature of riming. The classification of the dominant type of precipitation is based on GTB2015 (see Sect. 2.1.1).

\subsection{Riming and snowfall accumulation}

Riming is among the most efficient collisional mechanisms to increase the mass flux of precipitation (Houze and Medina, 2005). Firstly, it captures SLW droplets that would otherwise remain suspended or precipitate with much lower speed. Secondly, it increases the density and smooths the edge of ice-phase hydrometeors, thus leading to higher fall velocities and mass fluxes (e.g., Pruppacher and Klett, 1997; Garrett and Yuter, 2014).

Even though the link between rimed precipitation and snowfall amount is understandable, very few studies have tried to address it explicitly. Noteworthy exceptions are the studies of Harimaya and Sato (1989) and Mitchell et al. (1990), who analyzed snowfall already deposited on the ground. In a recent study, Colle et al. (2014) measured the degree of riming (as defined in Mosimann et al., 1994) of falling snow during 12 precipitation events in the northeast of the USA. Even though the focus of their work was not on the relation between riming and snowfall intensity, their measurements (see Table 1 of Colle et al., 2014) qualitatively show that the lowest snow accumulation rates are associated with lightly rimed or unrimed precipitation, while larger accumulation rates are associated with moderately to heavily rimed precipitation cases.

For the database of CLACE 2014 we make use of the radar-based classification scheme GTB2015 to quantify the amount of rimed precipitation. Let us define the percentage of rimed precipitation (PRP) as

$$
\begin{aligned}
& \operatorname{PRP}\left(h_{1}, h_{2}, \Delta t\right)= \\
& \quad 100 \frac{N(\mathrm{RI})}{N(\mathrm{RI})+N(\mathrm{AG})+N(\mathrm{CR})}\left(h_{1}, h_{2}, \Delta t\right) .
\end{aligned}
$$

PRP $(\%)$ defines the percentage of valid radar observations where riming is identified, between altitudes of $h_{1}$ and $h_{2}$ $(\mathrm{m})$ and within a given time interval $\Delta t . N(\mathrm{RI}), N(\mathrm{AG})$, and $N(\mathrm{CR})$ are the number of radar pixels classified as rimed ice, aggregates, and crystals, respectively (GTB2015).

Figure 2 shows the comparison between PRP, calculated at the temporal scale of entire precipitation events, and the mean accumulation rate of snow measured at the MAE site for the events of CLACE 2014. PRP is calculated considering $h_{1}=2200 \mathrm{~m}$ (i.e., the altitude of the MAE station) and varying $h_{2}$ between 2250 and $4000 \mathrm{~m}$, from which the error bars shown in the figure originate. It is worth noting that on average accumulation rate scales well with PRP. In particular, the events characterized by near-zero PRP are also associated with near-zero accumulation rates (e.g., events $1,2,11,8$ ), and all the events showing non-negligible accumulation rates also have proportionally higher PRP. We do not aim to provide final quantitative relations between these variables. Nevertheless, Fig. 2 shows also a regression line, corresponding to a correlation coefficient of 0.7 between PRP and snowfall accumulation rate. Similar trends were observed when a different hydrometeor classification method was employed (i.e., the method of Dolan and Rutledge, 2009, not shown here). The relation between riming and snowfall intensity was also qualitatively observed by Schneebeli et al. (2013) in a different location in the Swiss Alps. It must be noted that these results rely on radar-based hydrometeor classification (i.e., indirect measurements), and also that riming does not exclude 


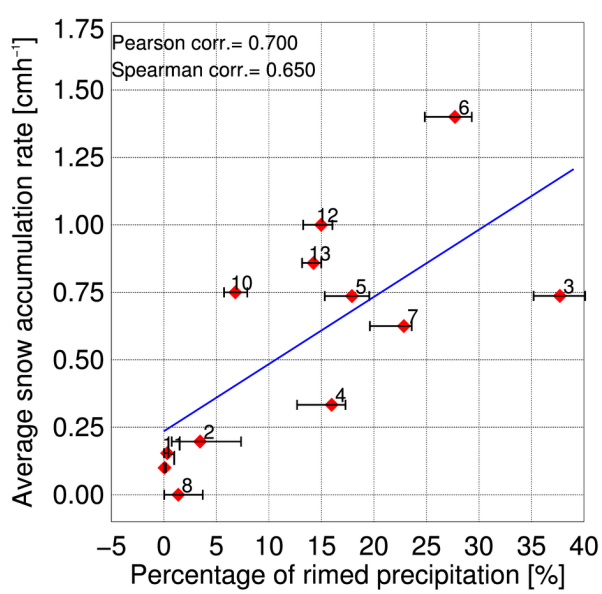

Figure 2. Relation between the percentage of rimed precipitation (PRP, retrieved by means of radar data) and mean snowfall accumulation rate, for the events listed in Table 1 . The error bars represent the 5 and $95 \%$ quantiles of PRP values calculated for maximum altitudes $z_{2}$ (in Eq. 1) varying between 2250 and $4000 \mathrm{~m}$. A linear regression line is displayed in blue.

the occurrence of other microphysical processes, notably aggregation.

\subsection{Evolution of rimed precipitation events}

Rimed precipitation, as defined in the previous section, mostly occurs during limited time intervals and not during the entire precipitation event. In this section we will analyze the most representative time steps identified by GTB2015 as rimed precipitation and we will compare the measurements of MXPol with the in situ information of the instruments deployed at JFJ.

The most representative cases in this sense are identified by means of the following constraints: (i) duration of at least half an hour, (ii) average PRP above $50 \%$ (with $h_{1}=2250 \mathrm{~m}$ and $h_{2}=\infty$ in Eq. 1), and (iii) peaks of at least 15 min characterized by PRP greater than $75 \%$ for all the altitudes below JFJ. The first constraint is justified by the need for collecting a statistically significant number of radar observations at the JFJ height (over a domain of approximately $20 \mathrm{~km}$ ) to be compared with the in situ measurements of much higher temporal resolution but collected at a single location. The second constraint ensures that more than $50 \%$ of precipitation, as classified by GTB2015, is rimed, while the third ensures that a large amount of rimed precipitation is also reaching ground level.

Figure 3 summarizes the bulk characteristics of the 6 representative cases isolated in this way. These events are named after the time interval of Table 1 that they belong to and are listed in Table 2. Panel a puts these cases into a context of snow accumulation. All the cases in the figure, with the exception of EV4, exhibit above-average snowfall intensities. One of them in particular, EV3, stands out because only
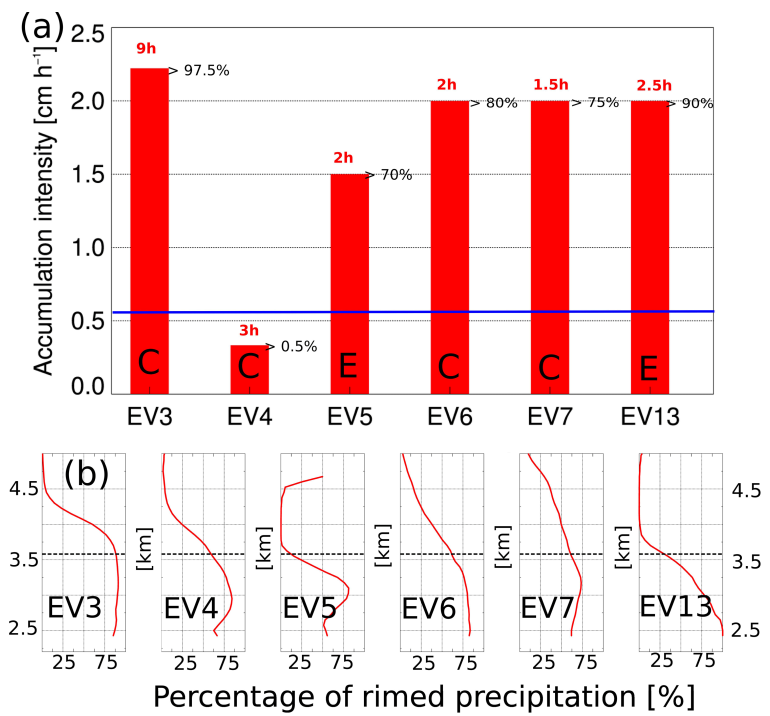

Figure 3. Summary characteristics of the six cases where riming is identified as the dominant mechanism (as listed in Table 2). (a) Mean snowfall accumulation intensity measured at MAE. The red number on top of each bar indicates the duration of the rimed time period. The numbers on the right side of the bars are the closest quantiles of the distribution of all snowfall events of the same duration in the same location (data from 2000 to 2014). The letters $\mathrm{C}$ and E refer to cases indicated in the text as "core" and "edge", respectively. The blue line indicates the mean value (during precipitation only) of CLACE 2014. (b) Average vertical profile of the percentage of rimed precipitation PRP (\%) during the selected time periods.

Table 2. List of the six rimed phases, subset of the events of Table 1, during which rimed precipitation was dominant according to the radar-based GTB2015 classifier.

\begin{tabular}{lrr}
\hline Label & $\begin{array}{r}\text { Start (UTC) } \\
\text { MM-DD HH }\end{array}$ & $\begin{array}{r}\text { Duration } \\
\text { (h) }\end{array}$ \\
\hline EV3 & 02-01 17:00 & 9 \\
EV4 & $02-0400: 00$ & 3 \\
EV5 & $02-0518: 00$ & 2 \\
EV6 & $02-0708: 30$ & 2 \\
EV7 & $02-0820: 00$ & 1.5 \\
EV13 & $02-2219: 30$ & 2.5 \\
\hline
\end{tabular}

$2.5 \%$ of the snowfall time intervals of the same duration occurring during the winter seasons (October-April) from 2000 to 2014 had higher intensities. Panel b is intended to show, for each case, average vertical profiles of PRP and to highlight the relative position of JFJ (indicated by a dashed black line) within each snow storm. During EV3, EV4, EV6 and EV7, PRP is close to its maximum values at the altitude of the JFJ site. In the present section only, we will refer to those events as "core events" and will add a subscript $\mathrm{C}$ to their name to indicate that the instruments of the JFJ site were located in the core of the main riming region. However, during 

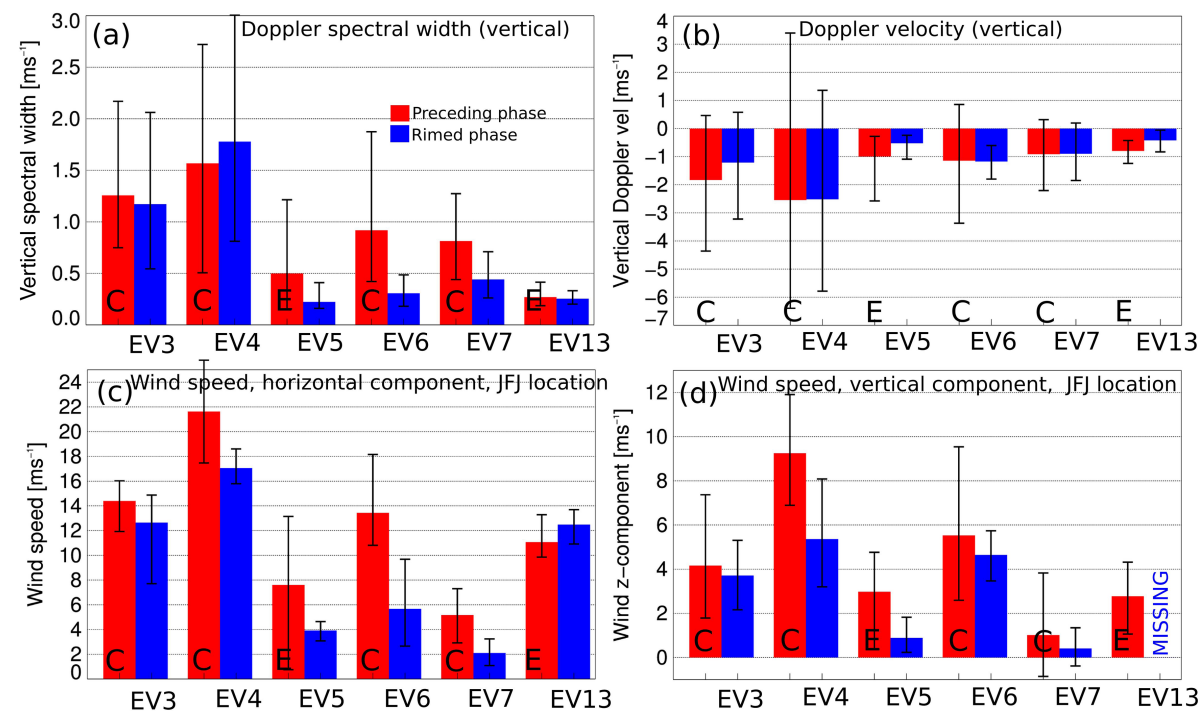

Figure 4. Measurements of wind, turbulence, and fall velocities before (red histograms) and during (blue histograms) the six "rimed phases" shown in Fig. 3. Panels (a) and (b) show radar data (only for altitude around the JFJ location: $3580 \pm 100 \mathrm{~m}$ ), while panels (c) and (d) show data collected at the JFJ location. (a) Doppler spectral width $\left(\mathrm{m} \mathrm{s}^{-1}\right)$ from radar vertical profiles (i.e., at vertical incidence). (b) Doppler velocity $\left(\mathrm{m} \mathrm{s}^{-1}\right)$ from radar vertical profiles. (c) Wind speed (data from MeteoSwiss station) ( $\mathrm{m} \mathrm{s}^{-1}$ ). (d) Vertical component of the wind (sonic anemometer data) $\left(\mathrm{m} \mathrm{s}^{-1}\right)$. The error bars highlight the location of the 5 and $95 \%$ quantiles, respectively.

EV5 and EV13, JFJ is located above the main riming region and we will refer to them as "edge events" and add a subscript E.

In the following, we analyze the characteristics of the described cases by means of radar observations and in situ measurements. Each case of interest, which we will refer to as "rimed phase", is compared with a reference time interval covering the 3 previous hours, referred to as the "preceding phase". Such a comparison is shown in Figs. 4 and 5. Figure 4 illustrates the behavior of horizontal and vertical wind, mean Doppler velocity, and Doppler spectral width, while Fig. 5 illustrates the evolution of radar horizontal reflectivity $Z_{\mathrm{H}}$ and in situ LWC during the selected cases.

\subsubsection{Edge events $\left(\mathrm{EV}_{\mathrm{E}}, \mathrm{EV13} \mathrm{E}_{\mathrm{E}}\right)$}

$\mathrm{EV} 5_{\mathrm{E}}$ and $\mathrm{EV} 13_{\mathrm{E}}$ have been sampled, from the JFJ perspective, above the actual "rimed core" of precipitation (see Fig. 3b). We can observe in Fig. 5b that they show the lowest $Z_{\mathrm{H}}$ values at the JFJ height during the rimed phase of the event. As $Z_{\mathrm{H}}$ in our observations increases with decreasing altitude, these two events are sampled closer to the cloud top than the other ones. Therefore, the in situ measurements in this case provide information about the processes occurring at the highest levels of rimed precipitation. Liquid water is available during both events (Fig. 5a), in much higher concentration during $\mathrm{EV} 13_{\mathrm{E}}$, and it is not depleted as the event evolves.
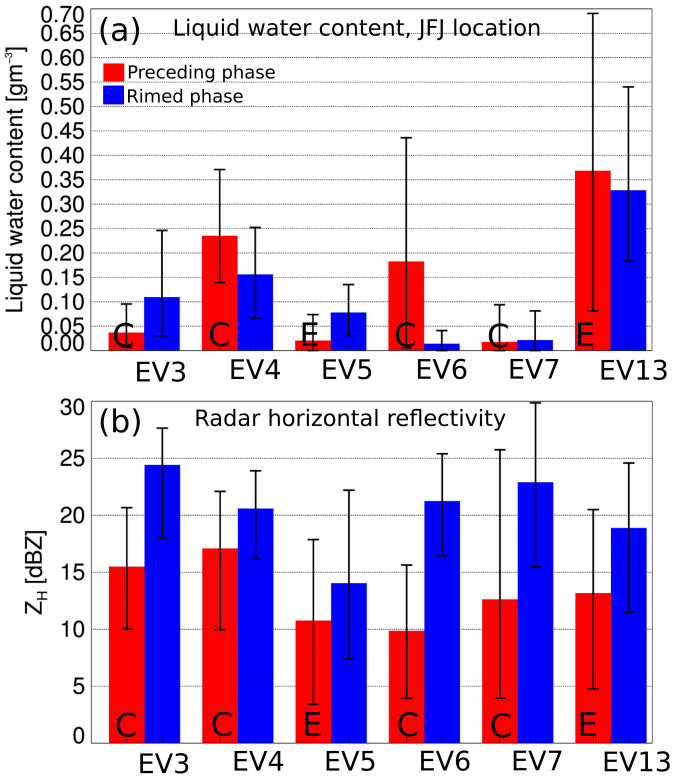

Figure 5. As in Fig. 4 but for $Z_{\mathrm{H}}$ and LWC. (a) Liquid water content LWC $\left(\mathrm{g} \mathrm{m}^{-3}\right)$ measured at the JFJ location. (b) Radar horizontal reflectivity factor $Z_{\mathrm{H}}(\mathrm{dBZ})$ from altitudes around the JFJ location: $3580 \pm 100 \mathrm{~m}$.

\subsubsection{Core events $\left(\mathrm{EV}_{\mathrm{C}}, \mathrm{EV}_{\mathrm{C}}, \mathrm{EV6}_{\mathrm{C}}, \mathrm{EV}_{\mathrm{C}}\right)$}

The "core" events are of major interest for the microphysical descriptions presented in the present paper. EV6 $6_{\mathrm{C}}$ and $\mathrm{EV7}_{\mathrm{C}}$ show similar qualitative trends in the transition be- 
tween the preceding phase and the rimed phase. Horizontal wind speed, vertical wind speed, Doppler spectral width, and the variability (interquantile range) in the mean Doppler velocity are lower during the rimed phases (blue histograms) than during the respective preceding phases (red histograms) as shown in Fig. 4. Doppler spectral width, shown in panel a, reduces by about $50 \%$, and horizontal (panel c) and vertical wind speed (panel d) also reduce. The mean Doppler velocity (panel b), influenced by particle fall velocity and air motion, shows positive values (meaning that the updraft was strong enough to lift the hydrometeors) and a larger variability during the preceding phase around mean values ranging between -2.3 and $-0.5 \mathrm{~m} \mathrm{~s}^{-1}$, as to be expected for aggregates and/or rimed hydrometeors (Brandes et al., 2008; Garrett and Yuter, 2014). It can be hypothesized that the initially active conditions of wind speed, variability, and updraft create the appropriate environment to generate rimed precipitation, which falls out efficiently during the following calmer part. Motion variability, wind gusts, updraft and turbulence are in fact important factors leading to riming by providing SLW droplets and conditions that favor collision (Rauber and Tokay, 1991; Pinsky and Khain, 1998; Houze and Medina, 2005). Aggregation of individual ice crystals is also favored by the variability and enhancement of particle velocities, and in turn aggregates provide larger SLW collection areas (Houze and Medina, 2005).

As observed in Fig. 5, during EV7 $\mathrm{C}$ the liquid water content is always low, before and during the rimed phase, suggesting that, in this case, riming occurred at much higher altitudes. The significant vertical extension of this snowfall event, as shown in Fig. 3b, with respect to the other events is in favor of this hypothesis. $\mathrm{EV6}_{\mathrm{C}}$ exhibits a very interesting LWC trend. LWC is practically entirely depleted before the rimed phase, with a transition of maximum values from around $0.45 \mathrm{~g} \mathrm{~m}^{-3}$ to around $0.05 \mathrm{~g} \mathrm{~m}^{-3}$. We believe that this is the actual signature of the efficient mass transfer due to riming, from the liquid mass suspended in the clouds to the ice mass that precipitates. In the rimed phase of the event, the LWC is collected in the form of rimed accretion, especially on the largest precipitating hydrometeors, and therefore it is not available any more in the form of water droplets.

The trends of $E V 4_{C}$ are similar to $E V 6_{C}$ (except for the Doppler spectral width), even though the magnitudes of the variables are very different. Also, in this case, a significant decrease in updraft occurrences and horizontal and vertical wind intensities (Fig. 4) can be observed, as well as a decrease in LWC (Fig. 5a) in the transition between the preceding phase and rimed phase. Horizontal wind speeds remain extremely high, with the $5 \%$ quantile never below $16 \mathrm{~m} \mathrm{~s}^{-1}$. Such wind intensities affect the snowfall flux towards the ground and introduce significant uncertainty in snow accumulation measurements. This probably explains why this case did not generate any significant response in terms of snowfall accumulation (Fig. 3a).
$\mathrm{EV} 3_{\mathrm{C}}$ is the most interesting one because it shows opposite trends with respect to $\mathrm{EV}_{\mathrm{C}}$ and $\mathrm{EV7}_{\mathrm{C}}$ for LWC. Notably, LWC is higher this time during the rimed phase (Fig. 5a), while Doppler spectral width and wind intensities (horizontal and vertical) decrease very slightly and remain very stable. This case, occurring during event number 3 in Table 1, lasted about $9 \mathrm{~h}$, was about three times longer than the second longest "rimed" case, and had an average snowfall intensity of more than $2.1 \mathrm{~cm} \mathrm{~h}^{-1}$. This value represents a very high quantile of snowfall intensity in comparison with events of analogous duration in the same area (Fig. 3). For these reasons it will be further discussed in the next sections.

\subsection{Vertical structure}

One of the distinct advantages of high-resolution and easily transportable polarimetric radars is the potential to sample the vertical structure of precipitation even, like in the present case, in complex terrains. We interpret here the microphysical processes occurring during the most intense cases according to the vertical structure of polarimetric variables $\left(Z_{\mathrm{H}}\right.$, $Z_{\mathrm{DR}}, K_{\mathrm{dp}}$ and $\left.\rho_{\mathrm{hv}}\right)$ extracted from radar RHI scans. The evolution of these measurements varies among the different cases, but many common features, listed in the following, exist.

\subsubsection{Upper level of precipitation}

Figure 6 shows statistics of the vertical evolution of polarimetric variables for a selected RHI of $E V 3_{C}, E V 6_{C}$, and $\mathrm{EV7}_{\mathrm{C}}$. In the upper levels of precipitation (above $4.5 \mathrm{~km}$ for $E V 3_{C}$ and $E V 6_{C}$ and above $5 \mathrm{~km}$ for $\left.E V 7_{C}\right), Z_{\mathrm{H}}$ takes values around $10 \mathrm{dBZ}, Z_{\mathrm{DR}}$ is approximately $0 \mathrm{~dB}$ and $K_{\mathrm{dp}}$ is close to $0^{\circ} \mathrm{km}^{-1}$, indicating the presence of small ice crystals that, at the X-band radar wavelength, do not exhibit significant anisotropy (e.g., Andric et al., 2013, hereafter A2013). The copolar cross-correlation coefficient $\rho_{\mathrm{hv}}$ is relatively low $(\leq 0.99)$ in this region. This is probably a combined effect of low signal-to-noise ratio, which affects the accuracy of $\rho_{\mathrm{hv}}$ (Torlaschi and Gingras, 2003) and actual physical variability and heterogeneity of crystal shapes and habits within the radar sampling volumes (Andric et al., 2013).

\subsubsection{Intermediate level of precipitation}

Proceeding towards lower altitudes (from approximately $4.5 / 5 \mathrm{~km}$ down to $3.5 \mathrm{~km}$ in all the cases shown in Fig. 6), $Z_{\mathrm{H}}$ increases until almost approaching its peak values. Between 4 and $4.5 \mathrm{~km}$ we observe the highest values of $Z_{\mathrm{DR}}$ in the column, followed slightly below by the highest values of $K_{\text {dp }}$. The enhancement of $Z_{\mathrm{DR}}$ is often explained by the presence of ice crystals grown by vapor deposition, which promotes anisotropic shape enhancement (Takahashi, 2014; Andric et al., 2013), and that can be particularly efficient if SLW is present and the Wegener-Bergeron-Findeisen (WBF) process takes place (e.g., Pruppacher and Klett, 1997). The en- 

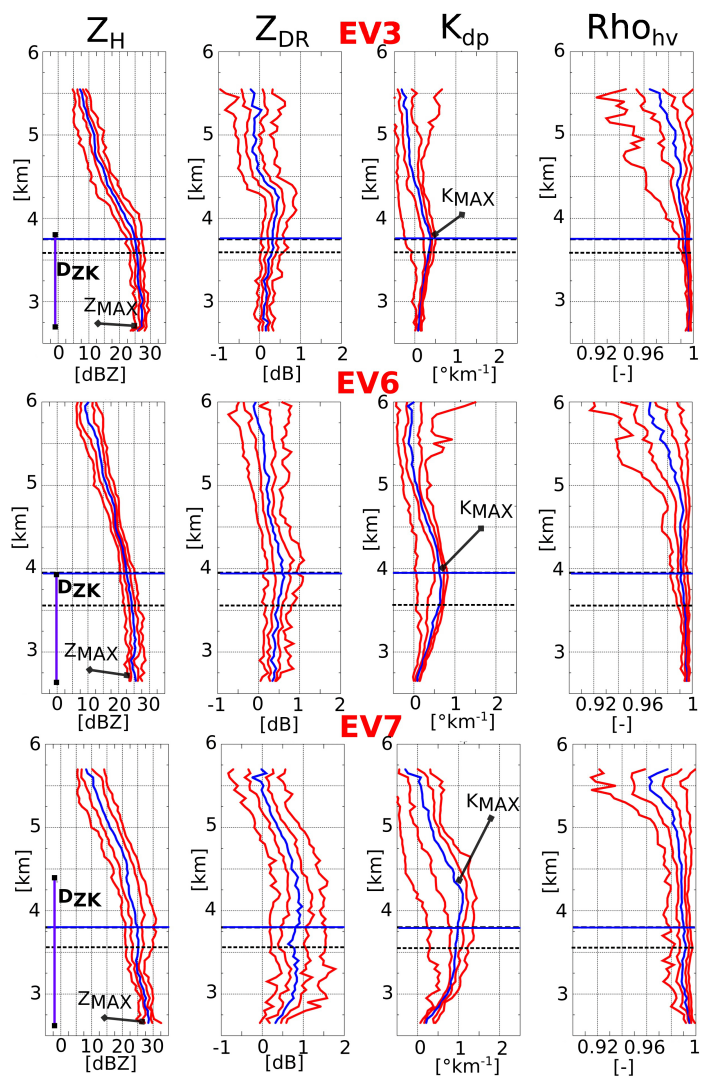

Figure 6. Vertical structure of polarimetric radar observations extracted from a single RHI of each selected case. The blue horizontal line indicates the estimated altitude of the $-15^{\circ} \mathrm{C}$ temperature level, extrapolated from in situ measurements collected at the JFJ location by means of a lapse rate with altitude of $-6.5^{\circ} \mathrm{km}^{-1}$. The dashed black line indicates the altitude of JFJ. The polarimetric variables are extracted considering a maximum elevation angle of $45^{\circ}$ (the effect of incidence is corrected with the method of Ryzhkov et al., 2005). The red curves indicate quantiles at 5, 25, 75 and $95 \%$, while the blue curve indicates the median. EV3 shows RHI data collected on 1 February 2014, 23:00 UTC. EV6 shows data collected on 7 February 2014, 10:05 UTC. EV7 shows data collected on 8 February 2014, 21:00 UTC.

hancement is in this case moderate, with peak values mostly below $1 \mathrm{~dB}$, suggesting that depositional growth is not the only process taking place and aggregation is initiated. In fact, $Z_{\mathrm{DR}}$ is largely influenced by the geometry of the particles that contribute the most to the $Z_{\mathrm{H}}$ signal (i.e., the biggest ones; Hubbert et al., 2014) such that the presence of even a few larger isotropic aggregates significantly decreases $Z_{\mathrm{DR}}$.

The peak of $K_{\mathrm{dp}}$, below altitudes of higher $Z_{\mathrm{DR}}$ and above altitudes of higher $Z_{\mathrm{H}}$, is a well-known but still not completely understood signature observed during snowfall (Kennedy and Rutledge, 2011; Bechini et al., 2013; Schneebeli et al., 2013; Andric et al., 2013; Hubbert et al., 2014). The proximity of this signature with respect to the $-15^{\circ} \mathrm{C}$ level (blue line in Fig. 6) has led in the past to it being asso- ciated with dendritic crystal growth (Kennedy and Rutledge, 2011). However, it was recognized that the concentration of dendrites needed to generate enhancements of this magnitude would lead to unreasonably high values of $Z_{\mathrm{H}}$ when these crystals eventually aggregate (Andric et al., 2013). It has been demonstrated that the particles responsible for these signatures must be small compared to the radar wavelength as they were shown to behave as Rayleigh scatterers by BBC2013 and Hubbert et al. (2014). BBC2013 and A2013 proposed two interesting and not mutually exclusive explanations. BBC2013 hypothesized that rimed dendrites would be able to generate such significant $K_{\mathrm{dp}}$ enhancement. $K_{\mathrm{dp}}$ is in fact increasing with the density of the oblate ice particles. A2013 suggested instead that secondary ice production of very small oblate crystals would need to take place to explain the $K_{\mathrm{dp}}$ signature, either as a result of splintering (Hallett and Mossop, 1974, or other multiplication mechanisms) or as a result of direct nucleation from the liquid phase with a similar process to that described in Westbrook and Illingworth (2011). Recent research (Schrom et al., 2015) has suggested, by means of particle size distribution retrievals based on scattering simulations, that a population of unrimed hydrometeors uniquely composed of aggregates and dendritic crystals may be able to generate the observed $K_{\mathrm{dp}}$ enhancement.

Our interpretation is that the region of enhanced $K_{\mathrm{dp}}$ is the radar signature of riming of anisotropic crystals. On the one hand, riming of already existing anisotropic crystals would enhance their contribution to $K_{\mathrm{dp}}$ by increasing the particle density and thus the dielectric response. On the other hand, the formation of secondary ice can also follow the mechanisms of Vardiman (1978) or Yano and Phillips (2011): less efficient and not constrained by temperature but favored by riming. In addition, the recently proposed mechanism of hoarfrost crystal lifting and transport (Lloyd et al., 2015) could be a secondary source of ice. Secondary ice would increase $K_{\mathrm{dp}}$ by enhancing the number concentration of ice crystals. The conditions favoring the collision of ice and liquid water droplets during riming also favors the ice-ice interaction and aggregation can be initiated. The newly formed aggregates will contribute to enhancement of $Z_{\mathrm{H}}$ while keeping $Z_{\mathrm{DR}}$ relatively low.

During $E V 3_{C}, E V 6_{C}$, and $E V 7_{C}$, the measurements of LWC, the presence of updrafts, and the variability and high intensity of the wind, as well as the radar-based classification (see Sect. 3.2), led us to a confident identification of riming at these altitude levels. Figure 7 displays the type of particles in the available size range 10 to $1280 \mu \mathrm{m}$ recorded at the level of JFJ by the 2D-S instrument, for $\mathrm{EV}_{\mathrm{C}}, \mathrm{EV} 6_{\mathrm{C}}$, and $\mathrm{EV} 7_{\mathrm{C}}$, respectively (at the same time steps shown in Fig. 6). During $\mathrm{EV}_{\mathrm{C}}$ and $\mathrm{EV}_{\mathrm{C}}$ we observe the presence of many particles with smooth shapes, interpreted as heavily rimed hydrometeors. Some of these hydrometeors do not have a recognizable original shape, some seem to probably originate from planar crystals, and columns and needles are observed dur- 


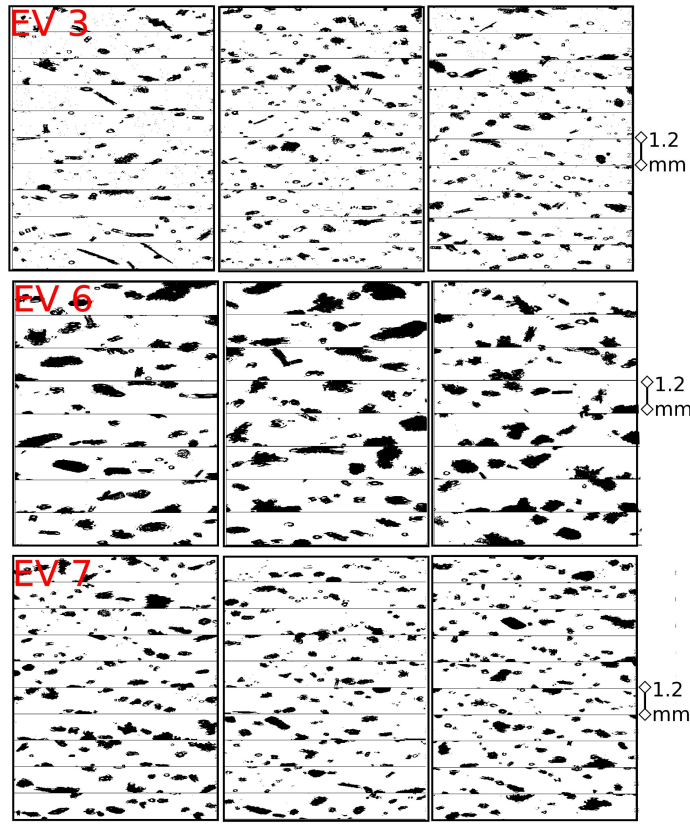

Figure 7. Particle images collected at the JFJ location by a 2D-S particle imager. Three cases are shown, corresponding to the polarimetric observations of Fig. 6. Top panel: EV3, on 1 February 2014, around 23:00 UTC. Middle panel: EV6 on 6 February 2014, around 10:00 UTC. Bottom panel: EV7 on 8 February 2014, around 21:00 UTC.

ing EV6. The ice particle number concentrations measured around these time steps ranged from 5 to $20 \mathrm{~L}^{-1}$ with modal values around $10 \mathrm{~L}^{-1}$ for $\mathrm{EV}_{\mathrm{C}}$ and from 5 to $23 \mathrm{~L}^{-1}$ with modal values around $10 \mathrm{~L}^{-1}$ for $\mathrm{EV7} \mathrm{C}^{1}$. The mean mass of the crystals in the size range sampled (obtained by dividing the total 2D-S ice mass content by the ice number concentration) during these time intervals was about 10 and $6 \mu \mathrm{g}$ during $E V 6_{C}$ and $E V 7_{C}$, respectively. During EV3 ${ }_{C}$, rimed crystals are observed together with a large number of small particles (some of them highly oblate, probably columns or needles) of various shapes. The ice number concentration around this time step ranged from 25 to $100 \mathrm{~L}^{-1}$ with modal values around $50 \mathrm{~L}^{-1}$ (larger than the case of $\mathrm{EV}_{\mathrm{C}}$ and $\mathrm{EV} 7_{\mathrm{C}}$ ) and the mean mass of the ice crystals was about $3.5 \mu \mathrm{g}$. We can hypothesize that, during $\mathrm{EV}_{\mathrm{C}}$ and $\mathrm{EV} 7_{\mathrm{C}}$, the $K_{\mathrm{dp}}$ signal is generated mostly by heavier riming of larger anisotropic crystals (but still in the Rayleigh regime), while during $\mathrm{EV} 3_{\mathrm{C}}$ it results from the higher concentration of smaller oblate particles. This is also confirmed by the higher values of $Z_{\mathrm{DR}}$ during $E V 6_{C}$ and $E V 7_{C}$ observed at the altitude of the JFJ site, especially if we recall that $Z_{\mathrm{DR}}$ is mostly influenced by the oblateness of larger particles. It is also worth noting, by looking at the particle images of Fig. 7 (and many others not shown here), that the $K_{\mathrm{dp}}$ enhancement seems not to be asso-

\footnotetext{
${ }^{1}$ These are reference values calculated within a 10 min time window. The given range of variation is based on 5 and $95 \%$ quantile.
}

ciated with pristine ice crystals habits. This suggests in this context that pristine unrimed dendrification may not be the dominant $K_{\mathrm{dp}}$ enhancement mechanism.

\subsubsection{Lower level of precipitation}

Returning to Fig. 6, below the $K_{\text {dp }}$ peak $Z_{\mathrm{H}}$ continues to increase, while both $K_{\mathrm{dp}}$ and $Z_{\mathrm{DR}}$ decrease steadily. Below altitude values of approximately $3.5 \mathrm{~km}$ (for all three cases), $Z_{\mathrm{DR}}$ and $K_{\mathrm{dp}}$ further decrease towards near-zero values and $Z_{\mathrm{H}}$ further increases, although at a lower rate. Aggregation is a mechanism that explains this trend (e.g., Kumjian et al., 2014). If aggregation is dominant, individual oblate crystals will be merged together into more spherical-like aggregates at a faster rate than they are produced. The presence of larger isotropic hydrometeors leads $Z_{\mathrm{H}}$ to increase and $Z_{\mathrm{DR}}$ to decrease, while the decrease in ice particle concentration and the consumption of oblate hydrometeors cause $K_{\mathrm{dp}}$ to decrease. Further riming, which may occur together with aggregation, can contribute to similar signatures only if the anisotropy of the hydrometeors is significantly reduced.

\subsection{4 $\quad Z_{\mathrm{H}}$ maxima and $K_{\mathrm{dp}}$ maxima}

As observed and documented in the present section, typical vertical profiles of polarimetric radar variables in snowfall in which riming has been identified show a maximum in $K_{\mathrm{dp}}$ at a certain altitude, as well as a maximum in $Z_{\mathrm{H}}$ usually at the lowest level of precipitation sampled by the radar (therefore suggesting a further increase at lower, non-sampled levels). The maximum in the median $K_{\mathrm{dp}}$ values per height level is labeled as $K_{\mathrm{MAX}}$ in Fig. 6, while its counterpart for $Z_{\mathrm{H}}$ is named $Z_{\mathrm{MAX}}$. The two quantities are situated at a vertical distance $D_{Z K}$ (positive if $K_{\mathrm{MAX}}$ is above $Z_{\mathrm{MAX}}$ ). Figure $8 \mathrm{a}$ shows the distribution of $D_{Z K}$ for all the RHIs collected during the six cases listed in Table 2 . It can be observed that $K_{\mathrm{MAX}}$ is indeed mostly above $Z_{\mathrm{MAX}}$ with a mean distance of about $680 \mathrm{~m}$. It is worth also noting that, in Fig. 8b, larger $K_{\mathrm{MAX}}$ values are also associated with larger $Z_{\mathrm{MAX}}$ even though the correlation between the quantities is weak $\left(r^{2} \approx 0.25\right)$. The peak of $K_{\mathrm{dp}}$ might therefore be considered an indication of high $Z_{\mathrm{H}}$ values at lower levels, as similar relations have been documented in other locations in Europe and North America (Kennedy and Rutledge, 2011; Bechini et al., 2013; Schrom et al., 2015).

\section{Case study (EV3): turbulence, wind shear, and snowfall enhancement}

\subsection{Detailed description of EV3}

We shall now come back to the peculiar case of EV3. EV3 occurred during the precipitation event leading to the largest snow accumulation (Fig. 2). There was an average precipitation intensity of $2.1 \mathrm{~cm} \mathrm{~h}^{-1}$ for a $9 \mathrm{~h}$ duration. Over the past 

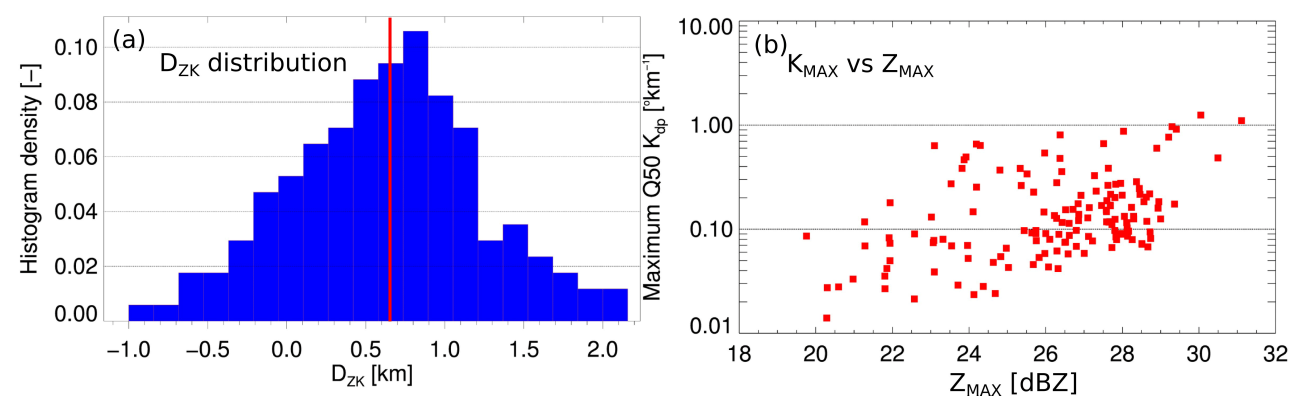

Figure 8. (a) Frequency distribution (i.e., sample histogram) of $D_{z k}(\mathrm{~km})$ values. (b) Scatterplot of $K_{\mathrm{MAX}}\left({ }^{\circ} \mathrm{km}^{-1}\right)$ vs. $Z_{\mathrm{MAX}}(\mathrm{dBZ})$. The graphs are calculated for all the time intervals listed in Table 2, and the quantities displayed are shown in Fig. 6.

(a)

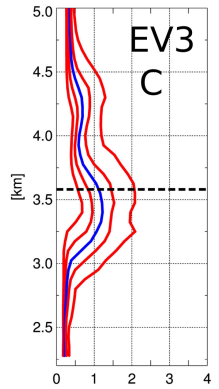

(b)

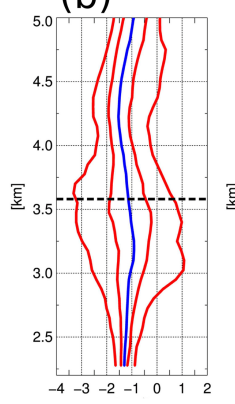

Doppler spectral width at vertical incidence $\left[\mathrm{ms}^{-1}\right]$
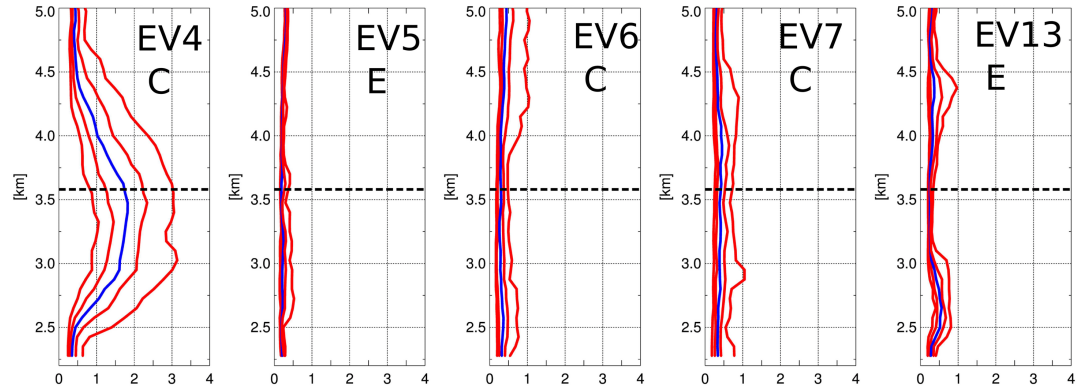

Mean Doppler velocity at vertical incidence [ms-1]
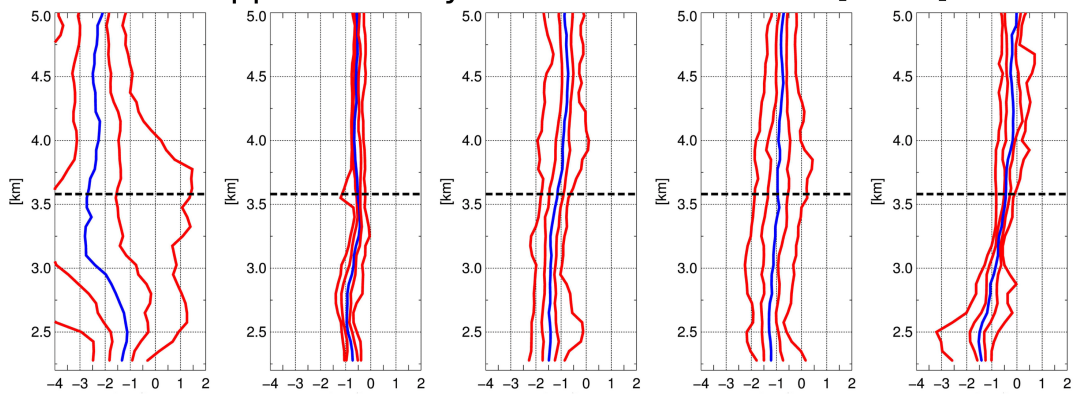

Figure 9. Vertical structure of (a) Doppler spectral width and (b) Doppler velocity over the whole duration of EV3, EV4, EV5, EV6, EV7, and EV13. Both variables are measured at vertical incidence.

14 years, according to the MAE measurement site, less than $2.5 \%$ of snowfall cases of this duration led to higher intensities. As documented in Fig. 5, SLW droplets were available during the whole event, and they were not rapidly depleted as happened in other cases. It is therefore instructive to investigate which mechanisms sustained the production of SLW and the significant snowfall. From the observations of Fig. 6, the vertical structure of EV3 appeared similar to the other "rimed" cases in terms of polarimetric variables. However, when looking at the average vertical structure of two Doppler-related radar variables (Doppler velocity and Doppler spectral width at vertical incidence) for the six cases of Table 2, an obvious difference emerges (Fig. 9). EV5, EV6, EV7 and EV13 do not exhibit particular signatures: the distribution of Doppler velocities is globally narrow and the occurrence of updrafts (positive values of Doppler ve- locity at vertical incidence) is very limited. Doppler spectral width values are lower than $1 \mathrm{~m} \mathrm{~s}^{-1}$, with median values always lower than $0.5 \mathrm{~m} \mathrm{~s}^{-1}$. EV4, however, is extremely variable over the whole range of heights: updrafts are frequent even at the lowest heights, and over all the heights, values of spectral width up to $3 \mathrm{~m} \mathrm{~s}^{-1}$ are observed. EV3, finally, shows a peculiarity: the enhancement of spectral width in this case appeared to be confined, above the radar location, between approximately 3000 and $4000 \mathrm{~m}$. In this layer the Doppler spectral width reaches values up to $2.5 \mathrm{~m} \mathrm{~s}^{-1}$ and mean Doppler velocities are often positive (updrafts), while at altitudes below $3000 \mathrm{~m}$ the range of variation in velocities and spectral width is narrower. We will refer to this as the "turbulent layer", meaning that the variability of hydrometeor motions within this area is governed by wind velocity variability and gusts overcoming the free-fall behavior of 

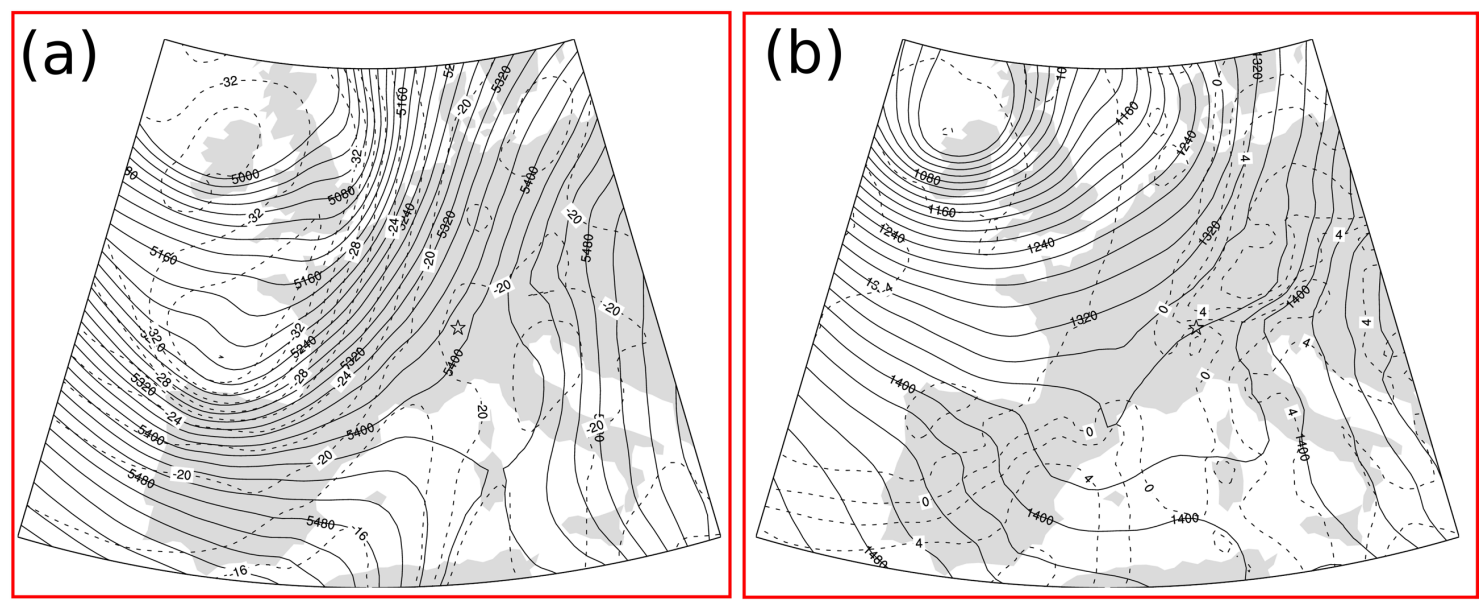

Figure 10. (a) $500 \mathrm{hPa}$ and (b) $850 \mathrm{hPa}$ geopotential height (m) (continuous lines) and temperature $\left({ }^{\circ} \mathrm{C}\right)$ (dashed lines) over central Europe at 12:00 UTC on 1 February 2014. The geographical location of the CLACE campaign is indicated by a star. The atmospheric fields are derived by ERA-Interim reanalysis grids at $0.5^{\circ} \times 0.5^{\circ}$ horizontal resolution.

particles. Additionally, the absence of multi-modal Doppler spectra (not shown here) led us to assume that the enhancement in spectral width is indeed mostly due to atmospheric turbulence and not to variability in particle fall velocities.

The synoptic situation occurring on 1 February at 12:00 UTC, just a few hours before the beginning of EV3, is represented in Fig. 10. The $500 \mathrm{hPa}$ geopotential height (panel a) shows the presence of a deep trough extending from the British Isles to western Europe, approaching the Alpine slopes from the west. Such a synoptic configuration has already been identified as responsible for heavy snowfalls in the alpine regions (Panziera and Hoskins, 2008). A cold front was associated with the trough, as is clearly visible from the $850 \mathrm{hPa}$ temperature shown in panel b. The atmospheric sounding of Payerne (lat $46.82^{\circ}$, long $6.94^{\circ}$ ) at 12:00 UTC, not shown here, indicates the presence of a strong southwesterly flow above $2 \mathrm{~km}$, which was probably producing high concentrations of SLW due to large-scale orographic lifting over the Alps. A southwesterly low-level jet was also observed between 1 and $1.3 \mathrm{~km}$. The sounding of 2 February at 00:00 UTC (not shown) reveals that, after the passage of the cold front, the temperature decreased by more than $10^{\circ} \mathrm{C}$ at an altitude of about $2 \mathrm{~km}$ over Payerne, consistent with the constant temperature drop which was also observed at the JFJ station in the afternoon. The passage of the cold front occurred between 21:00 and 00:00 UTC, as clearly shown by the measurements of atmospheric pressure collected at JFJ (see Fig. 11b), and by the sharp change in wind direction observed in Gütsch (lat $46.65^{\circ}$, long $8.61^{\circ}$, alt. $2283 \mathrm{~m}$ ), a nearby meteorological station not influenced by wind channeling as JFJ is. The snowfall event associated with the cold front produces a significant and steady accumulation of snowfall at ground level in MAE, as shown in Fig. 11a.
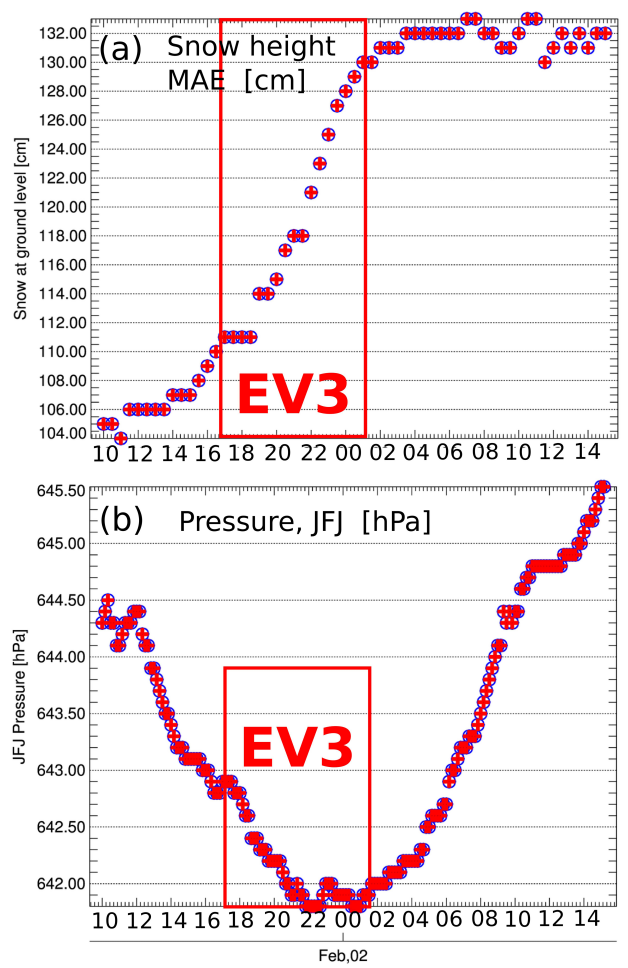

Figure 11. Evolution of (a) snow accumulation at ground level $(\mathrm{cm})$, measured at the MAE site, and (b) in situ environmental pressure $(\mathrm{hPa})$ measured at the JFJ location during EV3.

Figure 9 revealed the presence of a turbulent layer between 3000 and $4000 \mathrm{~m}$ altitude during EV3. Figures 12 and 13 illustrate the evolution of EV3 in a more complete and dynamic way. Figure 12a depicts the vertical structure of Doppler spectral width: the layer of enhanced spectral width and updrafts is clearly visible, and it is relatively stable in 

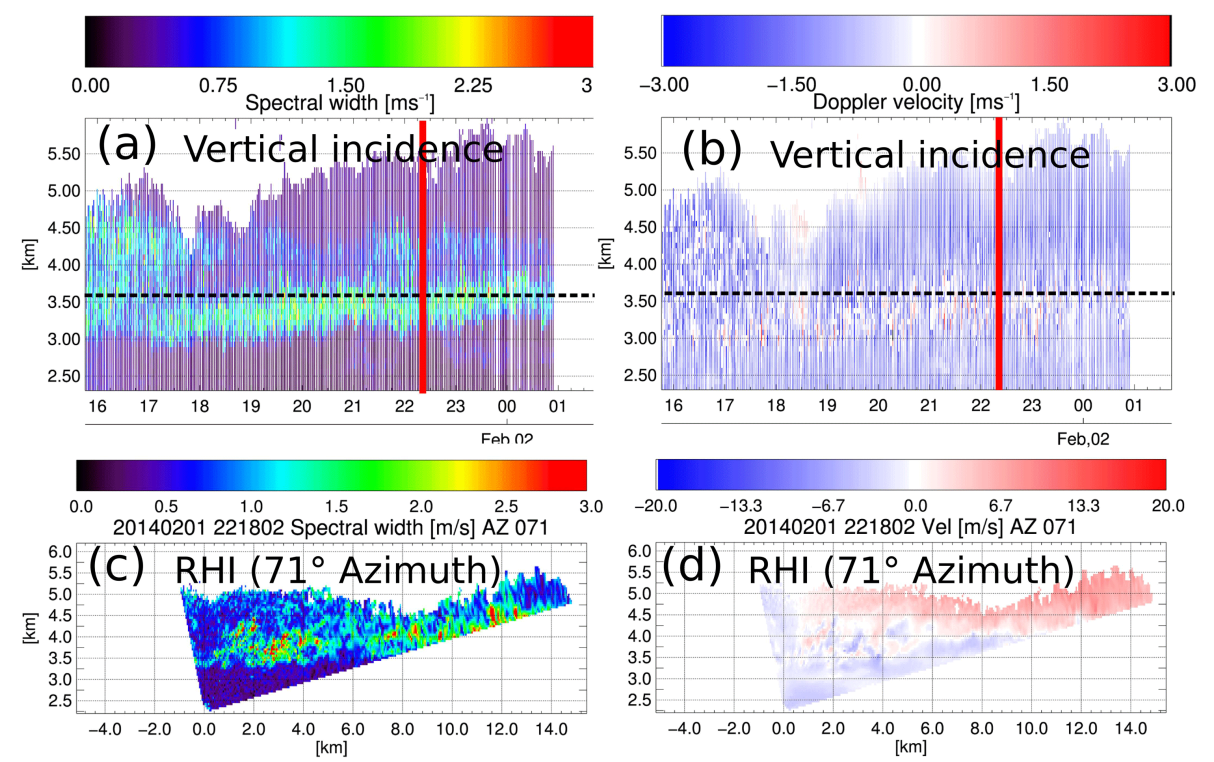

Figure 12. Time evolution of the vertical structure of Doppler-related variables during EV3. (a) Doppler spectral width at vertical incidence $\left(\mathrm{m} \mathrm{s}^{-1}\right)$. (b) Mean Doppler velocity at vertical incidence $\left(\mathrm{m} \mathrm{s}^{-1}\right)$, (c) RHI image of Doppler spectral width ( $\left.\mathrm{m} \mathrm{s}^{-1}\right)$, and (d) RHI image of mean Doppler velocity $\left(\mathrm{m} \mathrm{s}^{-1}\right)$. The horizontal black line in panels (a) and (b) indicates the altitude level of the JFJ site, while the vertical red line indicates the time of the RHIs in panels (c) and (d).

time. In Fig. 12b, showing the Doppler velocity at vertical incidence, we observe frequent positive values within the layer. Figure 12c and d show RHI data of Doppler spectral width and mean Doppler velocity, respectively, collected at 22:18 UTC. The layer where updrafts and enhanced spectral width are observed is situated at the interface of a change in sign of the Doppler velocity: two air masses with different relative motion with respect to the radar location are in contact. The change in sign of the Doppler velocities from negative to positive happens at the top of the turbulent layer, where the two air masses are mixing. Furthermore, we observe that the height of the top of this layer ranges from about $3.5 \mathrm{~km}$ (above the radar location) to about $4 \mathrm{~km}$ at a distance of about $10-15 \mathrm{~km}$. Because JFJ is situated at the altitudes where this active interface layer is observed, it is now possible to explain the availability of SLW at this level during EV3, documented in Fig. 5. This is in fact the result of the steady turbulent mixing and updrafts that lead to a constant generation of SLW. The rate of SLW input was probably higher than the collection efficiency of the ice particles within the layer itself, and therefore, despite the continuous collection, SLW remained in excess.

Below the wind shear we observe (Fig. 13) throughout the event the peak of $K_{\mathrm{dp}}$ and the steady increase in $Z_{\mathrm{H}}$ already discussed in relation to Fig. 5. $Z_{\mathrm{DR}}$ exhibits the same trends as in Fig. 5 and forms a cap of slightly enhanced values at the top of the turbulent layer.

\subsection{The role of small-scale turbulence and wind shear}

The role of turbulence in the generation and enhancement of snowfall has been documented by HM2005. HM2005 observed shear layers (and turbulent mixing within) associated with the interaction between baroclinic storms and mountain ranges (in both the Oregon Cascade Mountains and the Alps). An enhancement of precipitation was observed on the windward side of the mountain ranges during these cases. The enhancement was likely associated with intense aggregation and riming within the turbulent layer, which led to rapid fallout of water masses that would otherwise not be able to precipitate. The case depicted in the present paper is located in an inner-Alpine valley and not over the lower windward slopes of the mountains as in HM2005. While the consequences in terms of snow accumulation and the global microphysical interpretation of HM2005 are well applicable to our case, the reasons for the formation of the wind shear are different. In the present case, it is probably due to the orographic turbulence resulting from the interaction of the strong large-scale southwesterly flow with the main mountain peaks situated south of the KS location (see Fig. 1). It is worth noting, in support of this hypothesis, that the height of those peaks (about $4000 \mathrm{~m}$ ) corresponds roughly to the upper edge of the turbulent layer.

The effect of wind shear and turbulent recirculation on the microphysics of snowfall has been observed by Hogan et al. (2002), hereafter H2002. Also, in this case, the large-scale conditions and geographical locations described in H2002 are very different with respect to CLACE 2014. However, the 

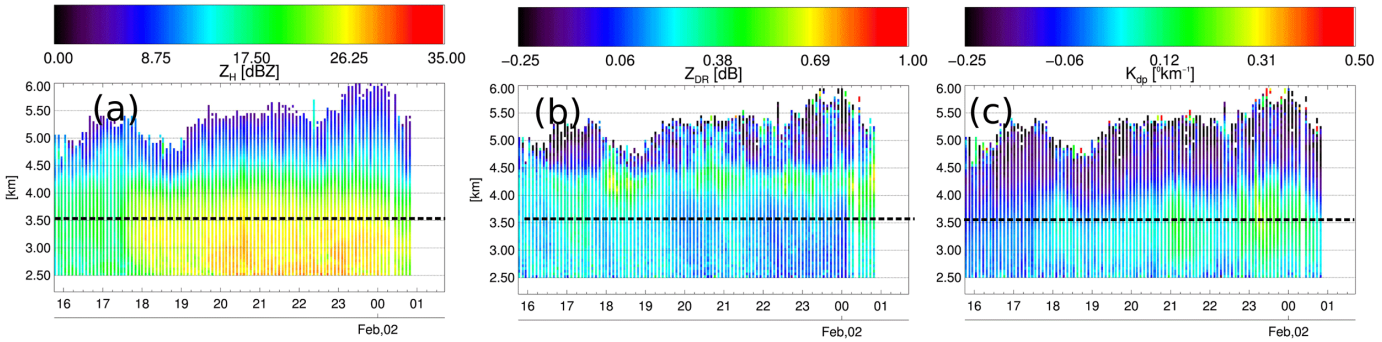

Figure 13. As in panels (a) or (b) of Fig. 12 but showing (a) $Z_{\mathrm{H}}(\mathrm{dBZ})$, (b) $Z_{\mathrm{DR}}(\mathrm{dB})$, and(c) $K_{\mathrm{dp}}\left({ }^{\circ} \mathrm{km}^{-1}\right)$. Note that panels (a) and (b) of Fig. 12 display data collected at vertical incidence, while in this image the data are mean-per-height values of RHI images.

microphysical processes described may also occur in alpine regions. In particular, H2002 explained that wind shear and updrafts together continuously feed the regions above the shear layer with SLW and ice fragments (generated by secondary ice production mechanisms) and favor the growth of anisotropic ice crystals at this level. This phenomenon creates an enhancement of $Z_{\mathrm{DR}}$, very similar to what we observe in our case in Fig. 13c. Additionally, H2002 recognized that secondary ice, by-product of the riming process, can be recirculated in the layer of shear and grow into oblate small ice particles like the ones that we can observe in Fig. 7. This mechanism, resulting in increased concentration of particles, can explain the enhancement of $K_{\mathrm{dp}}$ observed within the turbulent layer. It is worth noting that $K_{\mathrm{dp}}$ was unfortunately not available in the study of $\mathrm{H} 2002$. This variable has the definite advantage over $Z_{\mathrm{DR}}$ of being unbiased by the presence of large isotropic particles (like aggregates) that unavoidably are formed in areas of turbulent mixing. Regarding the generation of secondary ice, $\mathrm{H} 2002$ presented evidence for a Hallett-Mossop mechanism (HM hereafter; Hallett and Mossop, 1974), which occurs at temperatures warmer than $-8^{\circ} \mathrm{C}$. The enhancement of $K_{\mathrm{dp}}$ happens in our case at temperatures between -13 and $-16^{\circ} \mathrm{C}$, and although we observe the presence of columns and needles (as shown in Fig. 7), often produced when HM is active, this leads us to assume that other ice production mechanisms may be taking place. A first possible explanation would involve collisional mechanisms (e.g., Vardiman, 1978; Yano and Phillips, 2011) that require only earlier stages of riming and the presence of supercooled liquid water, ice crystals, and turbulence (all conditions that are met during EV3). A second explanation, recently proposed for the same measurement campaign of CLACE 2014 (Lloyd et al., 2015), would be the lifting and transport of hoarfrost crystals generated at ground level. During EV3 the environmental conditions are favorable to this process: wind and turbulence are significant (Fig. 4) and the main direction of propagation of the incoming front (southwesterly) leads the precipitation system to interact at first with the highest peaks in the region (Fig. 1), while the radar and in situ measurements are collected downwind (leeward) from them.

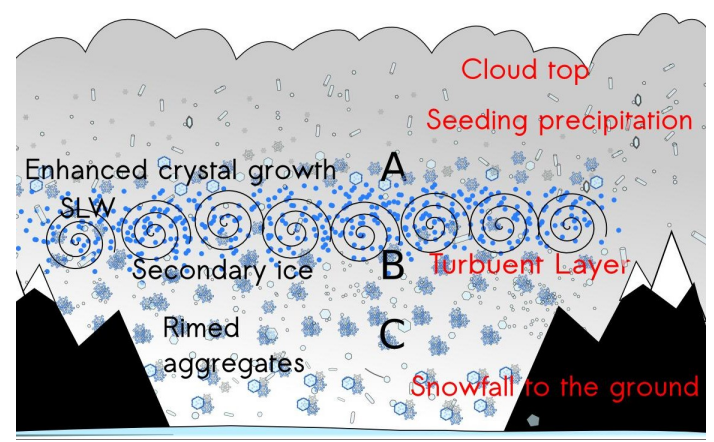

Figure 14. Schematic representation of the role of turbulence observed during EV3. The label "A" indicates area of enhanced $Z_{\mathrm{DR}}$, "B" indicates enhanced $K_{\mathrm{dp}}$, and "C" indicates enhanced $Z_{\mathrm{H}}$.

Figure 14 summarizes schematically the possible role that the turbulent layer was playing during EV3. Above the layer (enhanced $Z_{\mathrm{DR}}$ ), favorable conditions exist for anisotropic crystal growth thanks to the recirculation of SLW and ice fragments from the lower levels and to the supply of moisture (or SLW) provided by the large-scale southwesterly flow. Within the turbulent layer, aggregation and riming are initiated. Both riming itself and the availability of large quantities of small crystals, likely deriving from collisional ice multiplication, contribute to the peak of $K_{\mathrm{dp}}$. Aggregation and size sorting (e.g., Dawson et al., 2015) result in an increase in $Z_{\mathrm{H}}$ in the bottom part of the turbulent layer. Aggregation and further riming will then continue to raise $Z_{\mathrm{H}}$ until precipitation reaches the ground. In this global view, precipitation will be enhanced as long as the turbulent layer persists.

\section{Summary and conclusions}

This paper presented polarimetric radar and in situ measurements of precipitation in a mixed-phase cloud environment during CLACE 2014, in the central Alps of Switzerland. It was illustrated, thanks to the comparison between radar-based hydrometeor classification (i.e., indirect measurements) and actual measurements of snow accumulation, how riming correlates with snow accumulation rates. 
Most of the time, radar observations of precipitation classified as rimed were following time periods of updrafts, variability in wind and particle motions, and availability of SLW. When rimed precipitation was most intense, the conditions were usually quieter (thus favoring the precipitation) and SLW was depleted in the cores of rimed precipitation, being probably collected mostly in the form of rimed accretion on the precipitating ice crystals and also contributing to crystal growth in terms of depositional water vapor transfer on the ice phase at the expense of SLW droplets (WBF process). One noteworthy exception was a snowfall event referred to as EV3 (statistically, the most intense one). In this case, a stable layer of wind-shear-driven turbulence, associated with the passage of a cold front, created favorable conditions for the sustained production of SLW, ice-ice interaction, and efficient fallout of water masses by means of a mechanism similar to what was presented in Houze and Medina (2005). A microphysical interpretation of this mechanism has been proposed: anisotropic crystal growth dominates the areas just above the turbulent layer, while riming and aggregation are favored by the turbulent interactions.

The vertical structure of time intervals with intense snowfall has been examined by means of the radar polarimetric variables and in situ ice particle probes. A common feature of these cases was shown to be a peak of $K_{\mathrm{dp}}$, observed and documented in other published research, associated with either relatively large concentrations of small ice crystals (probably products of secondary ice generation or hoarfrost ice transport) or the riming of ice crystals with anisotropic shapes. The enhancement of $K_{\mathrm{dp}}$ has been shown to be related to the maximum $Z_{\mathrm{H}}$ measured in the vertical column of precipitation, as observed in previous research. Even though previous studies hypothesized the $K_{\mathrm{dp}}$ signature to be associated with dendritic growth, particle images (limited, however, to $1.28 \mathrm{~mm}$ of maximum sampling size) collected within this area of the storm did not show any evident or dominant pristine and unrimed dendritic habit in these cases.

The present study provided insight about the relation between riming and snow accumulation, the microphysics of riming, and the potential role of sustained turbulence on snowfall generation. It also illustrated the complementarity of in situ and remote sensing instruments for the description of snowfall microphysics in complex terrain. Future studies should include radar measurements at higher frequencies, lidar data, and passive remote sensors (e.g., radiometers) in order to better capture the transition between clouds and precipitation. Additionally, they should include in situ particle imagers of larger maximum sampling size in order to identify the hydrometeors that contribute most to the total $Z_{\mathrm{H}}$ signal and that are larger targets for riming. The potential role of turbulence in the microphysics and accumulation of snow should be further investigated in order to understand whether the patterns described for EV3 are recurring.
Acknowledgements. We are grateful to Erik Herrmann of the Paul Scherrer Institut for the organization of CLACE 2014. For the field deployment and maintenance of the instruments we thank Daniel Wolfensberger and Tim Raupach (EPFL-LTE) as well as all those from the Jungfrau railway and ski resort who assisted us during the installation of the radar. This work was supported by MeteoSwiss in the framework of the Global Atmosphere Watch program.

Edited by: T. Garrett

\section{References}

Abe, O.: Shear strength and angle of repose of snow layers including graupel, in: Annals of Glaciology, vol. 38, Int. Glaciol. Soc., Swiss Fed. Inst. Snow \& Avalanches, Davos, Switzerland, 305308, doi:10.3189/172756404781815149, 2004.

Andric, J., Kumjian, M. R., Zrnic, D. S., Straka, J. M., and Melnikov, V. M.: Polarimetric Signatures above the Melting Layer in Winter Storms: An Observational and Modeling Study, J. Appl. Meteorol. Clim., 52, 682-700, doi:10.1175/JAMC-D-12-028.1, 2013.

Avila, E. E., Castellano, N. E., Saunders, C. P. R., Buergesser, R. E., and Aguirre Varela, G. G.: Initial stages of the riming process on ice crystals, Geophys. Res. Lett., 36, L09808, doi:10.1029/2009GL037723, 2009.

Bailey, M. P. and Hallett, J.: A comprehensive habit diagram for atmospheric ice crystals: conformation from the laboratory, AIRS II, and other field studies, J. Atmos. Sci., 66, 2888-2899, doi:10.1175/2009JAS2883.1, 2009.

Baltensperger, U., Gaggeler, H. W., Jost, D. T., Lugauer, M., Schwikowski, M., Weingartner, E., and Seibert, P.: Aerosol climatology at the high-alpine site Jungfraujoch, Switzerland, J. Geophys. Res.-Atmos., 102, 19707-19715, doi:10.1029/97JD00928, 1997.

Bechini, R. and Chandrasekar, V.: A Semisupervised Robust Hydrometeor Classification Method for Dual-Polarization Radar Applications, J. Atmos. Ocean. Tech., 32, 22-47, doi:10.1175/JTECH-D-14-00097.1, 2015.

Bechini, R., Baldini, L., and Chandrasekar, V.: Polarimetric Radar Observations in the Ice Region of Precipitating Clouds at C-Band and X-Band Radar Frequencies, J. Appl. Meteorol. Clim., 52, 1147-1169, doi:10.1175/JAMC-D-12-055.1, 2013.

Brandes, E. A., Ikeda, K., Thompson, G., and Schoenhuber, M.: Aggregate Terminal Velocity/Temperature Relations, J. Appl. Meteorol. Clim., 4, 2729-2736, doi:10.1175/2008JAMC1869.1, 2008.

Bringi, V. N. and Chandrasekar, V.: Polarimetric doppler weather radar, Cambridge University Press, Cambridge, UK, 2001.

Cantrell, W. and Heymsfield, A.: Production of ice in tropospheric clouds, B. Am. Meteorol. Soc., 86, 795-897, doi:10.1175/BAMS-86-6-795, 2005.

Chen, J. P. and Lamb, D.: The theoretical basis for the parametrization of ice crystal habits - growth by vapordeposition, J. Atmos. Sci., 51, 1206-1221, doi:10.1175/15200469(1994)051<1206:TTBFTP>2.0.CO;2, 1994.

Colle, B. A., Stark, D., and Yuter, S. E.: Surface Microphysical Observations within East Coast Winter Storms on Long Island, New 
York, Mon. Weather Rev., 142, 3126-3146, doi:10.1175/MWRD-14-00035.1, 2014.

Dawson II, D. T., Mansell, E. R., and Kumjian, M. R.: Does Wind Shear Cause Hydrometeor Size Sorting?, J. Atmos. Sci., 72, 340348, doi:10.1175/JAS-D-14-0084.1, 2015.

Dolan, B. and Rutledge, S. A.: A theory-based hydrometeor identification algorithm for X-band polarimetric radars, J. Atmos. Ocean. Tech., 26, 2071-2088, doi:10.1175/2009JTECHA1208.1, 2009.

Doviak, R. and Zrnić, D.: Doppler radar and weather observations, 2nd edition, Dover Publications, Mineola, USA, 2006.

Fukuta, N. and Takahashi, T.: The growth of atmospheric ice crystals: A summary of findings in vertical supercooled cloud tunnel studies, J. Atmos. Sci., 56, 1963-1979, doi:10.1175/15200469(1999)056<1963:TGOAIC>2.0.CO;2, 1999.

Garrett, T. J. and Yuter, S. E.: Observed influence of riming, temperature, and turbulence on the fallspeed of solid precipitation, Geophys. Res. Lett., 41, 6515-6522, doi:10.1002/2014GL061016, 2014.

Grazioli, J., Tuia, D., and Berne, A.: Hydrometeor classification from polarimetric radar measurements: a clustering approach, Atmos. Meas. Tech., 8, 149-170, doi:10.5194/amt-8-149-2015, 2015.

Hallett, J. and Mossop, S. C.: Production of secondary ice particles during the riming process, Nature, 249, 26-28, doi:10.1038/249026a0, 1974.

Harimaya, T. and Sato, Y.: Measurement of the riming amount on snowflakes, J. Fac. Sci, Hokkaido University, 8, 355-366, 1989.

Hogan, R. J., Field, P. R., Illingworth, A. J., Cotton, R. J., and Choularton, T. W.: Properties of embedded convection in warm-frontal mixed-phase cloud from aircraft and polarimetric radar, Q. J. Roy. Meteor. Soc., 128, 451-476, doi:10.1256/003590002321042054, 2002.

Hogan, R. J., Francis, P. N., Flentje, H., Illingworth, A. J., Quante, M., and Pelon, J.: Characteristics of mixed-phase clouds. I: Lidar, radar and aircraft observations from CLARE'98, Q. J. Roy. Meteor. Soc., 129, 2089-2116, doi:10.1256/rj.01.208, 2003.

Houze, R. A. and Medina, S.: Turbulence as a mechanism for orographic precipitation enhancement, J. Atmos. Sci., 62, 35993623, 2005.

Hubbert, J. C., Ellis, S. M., Chang, W. Y., Rutledge, S., and Dixon, M.: Modeling and Interpretation of S-Band Ice Crystal Depolarization Signatures from Data Obtained by Simultaneously Transmitting Horizontally and Vertically Polarized Fields, J. Appl. Meteorol. Clim., 53, 1659-1677, doi:10.1175/JAMC-D13-0158.1, 2014.

Kennedy, P. C. and Rutledge, S. A.: S-band dual polarization radar observations of winter storms, J. Appl. Meteorol. Clim., 50, 844858, doi:10.1175/2010JAMC2558.1, 2011.

Kumjian, M. R., Rutledge, S. A., Rasmussen, R. M., Kennedy, P. C., and Dixon, M.: High-resolution polarimetric radar observations of snow-generating cells, J. Appl. Meteorol. Clim., 53, 16361658, doi:10.1175/JAMC-D-13-0312.1, 2014.

Lance, S., Brock, C. A., Rogers, D., and Gordon, J. A.: Water droplet calibration of the Cloud Droplet Probe (CDP) and inflight performance in liquid, ice and mixed-phase clouds during ARCPAC, Atmos. Meas. Tech., 3, 1683-1706, doi:10.5194/amt3-1683-2010, 2010.
Lawson, R. P., O’Connor, D., Zmarzly, P., Weaver, K., Baker, B., Mo, Q., and Jonsson, H.: The 2D-S (Stereo) probe: Design and preliminary tests of a new airborne, high-speed, high-resolution particle Imaging probe, J. Atmos. Ocean. Tech., 23, 1462-1477, doi:10.1175/JTECH1927.1, 2006.

Lloyd, G., Choularton, T. W., Bower, K. N., Gallagher, M. W., Connolly, P. J., Flynn, M., Farrington, R., Crosier, J., Schlenczek, O., Fugal, J., and Henneberger, J.: The origins of ice crystals measured in mixed-phase clouds at the high-alpine site Jungfraujoch, Atmos. Chem. Phys., 15, 12953-12969, doi:10.5194/acp15-12953-2015, 2015.

Magono, C. and Lee, C. W.: Meteorological classification of natural snow crystals, J. Fac. Sci., Hokkaido Univ., Series VII, 2, 321335, 1966.

Mitchell, D. L., Zhang, R., and Pitter, R. L.: Mass-dimensional relationships for ice particles and the inflluence of riming on snowfall rates, J. Appl. Meteor., 29, 153-163, doi:10.1175/15200450(1990)029<0153:MDRFIP>2.0.CO;2, 1990.

Mosimann, L., Weingartner, E., and Waldvogel, A.: An analysis of accreted drop sizes and mass on rimed snow crystals, J. Atmos. Sci., 51, 1548-1558, doi:10.1175/15200469(1994)051<1548:AAOADS>2.0.CO;2, 1994.

Ono, A.: The Shape and Riming Properties of Ice Crystals in Natural Clouds, J. Atmos. Sci., 26, 138-147, doi:10.1175/15200469(1969)026<0138:TSARPO>2.0.CO;2, 1969.

Panziera, L. and Hoskins, B.: Large snowfall events in the southeastern Alps, Weather, 63, 88-93, doi:10.1002/wea.178, 2008.

Pinsky, M. B. and Khain, A. P.: Some effects of cloud turbulence on water-ice and ice-ice collisions, Atmos. Res., 48, 69-86, 1998.

Pruppacher, H. R. and Klett, R. L.: Microphysics of clouds and precipitation, no. 18 in Atmospheric and Oceanographic Sciences Library, 2nd edn., Kluwer Academic Press, Dordrecht, the Netherlands, 1997.

Rangno, A. L.: Fragmentation of freezing drops in shallow maritime frontal clouds, J. Atmos. Sci., 65, 1455-1466, doi:10.1175/2007JAS2295.1, 2008.

Rauber, R. M. and Tokay, A.: An explanation for the existence of supercooled water at the top of cold clouds, J. Atmos. Sci., 48, 1005-1023, doi:10.1175/15200469(1991)048<1005:AEFTEO>2.0.CO;2, 1991.

Ryzhkov, A. V., Giangrande, S. E., Melnikov, V. M., and Schuur, T. J.: Calibration issues of dual-polarization radar measurements, J. Atmos. Ocean. Tech., 22, 1138-1155, doi:10.1175/JTECH1772.1, 2005.

Schneebeli, M., Dawes, N., Lehning, M., and Berne, A.: Highresolution vertical profiles of polarimetric X-band weather radar observables during snowfall in the Swiss Alps, J. Appl. Meteorol. Clim., 52, 378-394, doi:10.1175/JAMC-D-12-015.1, 2013.

Schrom, R. S., Kumjian, M. R., and Lu, Y.: Polarimetric radar signatures of dendritic growth zones within Colorado winter storms, J. Appl. Meteor. Clim., doi:10.1175/JAMC-D-15-0004.1, 2015.

Scipion, D., Mott, R., Lehning, M., Schneebeli, M., and Berne, A.: Seasonal small-scale spatial variability in alpine snowfall and snow accumulation, Water Resour. Res., 49, 1446-1457, doi:10.1002/wrcr.20135, 2013.

Straka, J. M. and Mansell, E. R.: A bulk microphysics parameterization with multiple ice precipitation categories, J. Appl. Meteor., 44, 445-466, doi:10.1175/JAM2211.1, 2005. 
Straka, J. M., Zrnic, D. S., and Ryzhkov, A. V.: Bulk hydrometeor classification and quantification using polarimetric radar data: synthesis of relations, J. Appl. Meteor., 39, 1341-1372, 2000.

Takahashi, T.: Influence of Liquid Water Content and Temperature on the Form and Growth of Branched Planar Snow Crystals in a Cloud, J. Atmos. Sci., 71, 4127-4142, doi:10.1175/JAS-D-140043.1, 2014.

Torlaschi, E. and Gingras, Y.: Standard Deviation of the Copolar Correlation Coefficient for Simultaneous Transmission and Reception of Vertical and Horizontal Polarized Weather Radar Signals, J. Atmos. Ocean. Tech., 20, 760-766, doi:10.1175/15200426(2003)20<760:SDOTCC>2.0.CO;2, 2003.

Vardiman, L.: The generation of secondary ice particles in clouds by crystal-crystal collision, J. Atmos. Sci., 35, 2168-2180, 1978.
Westbrook, C. D. and Illingworth, A. J.: Evidence that ice forms primarily in supercooled liquid clouds at temperatures > -27 degrees C, Geophys. Res. Lett., 38, L02824, doi:10.1029/2011GL048021, 2011.

Yano, J.-I. and Phillips, V. T. J.: Ice-ice collisions: An ice multiplication process in atmospheric clouds, J. Atmos. Sci., 68, 322-333, doi:10.1175/2010JAS3607.1, 2011.

Zieger, P., Kienast-Sjögren, E., Starace, M., von Bismarck, J., Bukowiecki, N., Baltensperger, U., Wienhold, F. G., Peter, T., Ruhtz, T., Collaud Coen, M., Vuilleumier, L., Maier, O., Emili, E., Popp, C., and Weingartner, E.: Spatial variation of aerosol optical properties around the high-alpine site Jungfraujoch (3580 ma.s.1.), Atmos. Chem. Phys., 12, 72317249, doi:10.5194/acp-12-7231-2012, 2012. 